\title{
Intervenções farmacêuticas e seus desfechos em portadores de HIV/AIDS em atendimento de média complexidade
}

\author{
Pharmaceutical interventions and their outcomes in HIV/AIDS patients in medium \\ complexity care
}
Intervenciones farmacéuticas y sus resultados en pacientes con VIH/SIDA en atención de complejidad media

Jorgete Carneiro Chaves ${ }^{1 *}$, Ana Cristina Lo Prete ${ }^{2}$, Orenzio Soler ${ }^{1}$, Carolina Heitmann Mares Azevedo Ribeiro' ${ }^{1}$.

\section{RESUMO}

Objetivo: Investigar evidências sobre tipos de intervenções, dando ênfase às intervenções farmacêuticas, e seus respectivos desfechos clínicos, epidemiológicos, de acesso, humanístico e econômicos em portadores de HIV/Aids em atendimento de média complexidade. Métodos: Revisão sistemática com estratégia de busca nos estudos publicados nas bases Cochrane Library, Epistemonikos, Health Evidence, Health Systems Evidence, Biblioteca Virtual de Saúde e Google Scholar; incluindo Medical Subject Headings (MeSH) e Descritores em Ciências da Saúde (DeCS), incluindo os domínios "Pharmaceutical attention", "Pharmaceutical Care", "Pharmaceutical Interventions", "Pharmaceutical Services", "HIVIAIDS", "Medium Complexity Attention" e "Medium Complexity Care", sendo adaptada para as distintas bases eletrônicas, utilizando-se dos operadores booleanos OR e AND. Resultados: Há evidências de que as intervenções farmacêuticas profissionais, financeiras, governamentais e multifacetadas, melhoram os desfechos clínicos, epidemiológicos, de acesso e equidade, humanístico e econômicos em portadores de HIV/Aids em atendimento de média complexidade. Considerações finais: Diversas intervenções farmacêuticas ao portador de HIV/Aids se mostraram importantes na melhora de desfechos clínicos, epidemiológicos, humanísticos e de acesso e equidade, tendo assim o cuidado farmacêutico se mostrado importante para fortalecer as estratégias do uso racional de medicamentos e promovendo a melhoria da qualidade de vida do paciente.

Palavras-chave: Serviços farmacêuticos, HIV, AIDS, Média complexidade.

\begin{abstract}
Objective: Investigate evidence on types of interventions, emphasizing pharmaceutical interventions, and their respective clinical, epidemiological, access, humanistic and economic outcomes in patients with HIV / AIDS in medium complexity care. Methods: Systematic review and narrative synthesis. Results: there is evidence that professional, financial, governmental and multifaceted pharmaceutical interventions improve clinical, epidemiological, access and equity, humanistic and economic outcomes in people with HIV / AIDS in medium complexity care. Results: There is evidence that professional, financial, governmental and multifaceted pharmaceutical interventions improve clinical, epidemiological, access and equity, humanistic and economic outcomes in people with HIV / AIDS in medium complexity care. Final considerations: Several pharmaceutical interventions for people with HIV / AIDS have been shown to be important in improving clinical, epidemiological, humanistic and access and equity outcomes, thus pharmaceutical care has been shown to be important in strengthening strategies for the rational use of medicines and promoting quality improvement of the patient's life.
\end{abstract}

Keywords: Pharmaceutical services, HIV, AIDS, Medium complexity.

1 Universidade Federal do Pará (UFPA), Belém - PA. *E-mail: jorgetecarneiro@hotmail.com

2 Universidade São Judas Tadeu (USJT), São Paulo - SP. 


\section{RESUMEN}

Objetivo: Investigar evidencia sobre tipos de intervenciones, enfatizando las intervenciones farmacéuticas y sus respectivos resultados clínicos, epidemiológicos, de acceso, humanísticos y económicos en pacientes con VIH / SIDA en cuidados de complejidad media. Métodos: Revisión sistemática con estrategia de búsqueda en estudios publicados en las bases de datos Cochrane Library, Epistemonikos, Health Evidence, Health Systems Evidence, Virtual Health Library y Google Scholar; incluidos los encabezados de temas médicos (MeSH) y los descriptores de ciencias de la salud (DeCS), incluidos los dominios "Atención farmacéutica", "Atención farmacéutica", "Intervenciones farmacéuticas", "Servicios farmacéuticos", "VIH / SIDA", "Atención de complejidad media" y "Cuidado de Complejidad Media", siendo adaptado para las diferentes bases electrónicas, utilizando los operadores booleanos OR y AND. Resultados: Existe evidencia de que las intervenciones farmacéuticas profesionales, financieras, gubernamentales y multifacéticas mejoran los resultados clínicos, epidemiológicos, de acceso y equidad, humanísticos y económicos en pacientes con VIH / SIDA en cuidados de complejidad media. Consideraciones finales: Varias intervenciones farmacéuticas para personas con VIH / SIDA han demostrado ser importantes para mejorar los resultados clínicos, epidemiológicos, humanísticos y de acceso y equidad, por lo que la atención farmacéutica ha demostrado ser importante para fortalecer las estrategias para el uso racional de los medicamentos y promover la mejora de la calidad de la vida del paciente.

Palabras clave: Servicios farmacéuticos, VIH, SIDA, Complejidad media.

\section{INTRODUÇÃO}

A Síndrome da Imunodeficiência Adquirida (SIDA); Acquired Immunodeficiency Syndrome (AIDS), causada pela infecção do Vírus da Imunodeficiência Humana (HIV), foi identificado em 1981 e, ainda hoje, constitui um sério problema de Saúde Pública em todo o mundo (BENZAKEN A, 2017). A infecção pelo HIV e a AIDS fazem parte da Lista Nacional de Notificação Compulsória de Doenças, sendo que a AIDS é de notificação compulsória desde 1986, e a infecção pelo HIV é de notificação compulsória desde 2014, tornando-se assim, obrigatória a comunicação de ocorrência de ambos os casos (BRASIL, 2018).

De acordo com o Boletim Epidemiológico Anual HIV/AIDS do Ministério da Saúde, estima-se que aproximadamente 37 milhões de pessoas no mundo estejam infectadas com o HIV. No Brasil em torno de 866 mil pessoas viviam com o HIV no ano passado, dos quais $84 \%$ (731 mil) haviam sido diagnosticadas e 75\% (548 mil) estavam em tratamento antirretroviral (BRASIL, 2018; DUNCOMBE CBA, et al., 2013).

Desde a descoberta da AIDS, importantes avanços foram alcançados no Brasil, iniciando-se com a sanção da Lei 9.313, de 13 de novembro de 1996, que dispõe sobre a obrigação do Estado de distribuir, de forma universal e gratuita, os medicamentos para Terapia Antirretroviral (TARV) (BRASIL, 1996; PRUST ML, et al., 2018). Especialmente com o advento da Terapia Antirretroviral de Alta Eficácia (HAART), a história natural da AIDS foi alterada, mudando o perfil da epidemia, resultando na melhora dos indicadores de morbidade, de mortalidade e de qualidade de vida do que intitularam "Pessoas Vivendo com HIV/AIDS" (PVHA) (PRIMO LP, 2015).

O Programa Nacional de DST/Aids (PN-DST/Aids) através do Sistema Único de Saúde (SUS), passou a disponibilizar prevenção combinada e saúde reprodutiva das PVHA, procurando apresentar estratégias para compreensão do cuidado integral e enfrentamento da epidemia, com melhoria da oferta de serviços e da qualidade de assistência à saúde aos pacientes, tornando o Brasil um dos pioneiros a atestar pelo SUS o direito igualitário e universal de acesso a medicamentos para o tratamento de doenças oportunistas e para os antirretrovirais (ABRÃO FMS, et al., 2014).

Além disso, conforme o Protocolo Clínico Brasileiro para o Manejo da Infecção pelo HIV em adultos, atualizado em 2017, o início da TARV é estimulado, independente da contagem de linfócitos T CD4+, na perspectiva de redução da transmissibilidade do HIV (CASAGRANDE BJ, 2019).

Estas conquistas contribuíram para que na atualidade, a infecção pelo vírus HIV se tornasse uma doença de caráter crônico e controlável, possibilitando a reinserção social das PVHA, com retomada nas rotinas diárias e profissionais (MORILLO-VERDUGO RM, et al., 2017). Entretanto, o sucesso terapêutico requer níveis elevados de adesão ao tratamento, com o uso diário e contínuo, na dose e horário corretos, necessários para que ocorra a supressão da replicação viral e melhora imunológica e de outros desfechos clínicos. 
Além de que os aspectos epidemiológicos, de acesso e econômicos, que podem dificultar a aquisição dos medicamentos, assim como questões humanísticas de acolhimento do paciente, também impactam na adesão ao tratamento. Tais medidas visam tanto a redução do risco de desenvolver resistência aos TARV, como de transmissão do vírus HIV, o que ainda é um grande desafio a ser vencido (HOSSEINI Z, et al., 2016).

O presente estudo tem por objetivo investigar evidências sobre tipos de intervenções farmacêuticas e seus respectivos desfechos clínicos, epidemiológicos, de acesso, humanístico e econômicos em portadores de HIV/AIDS em atendimento de média complexidade.

\section{MÉTODOS}

Trata-se de uma Revisão Sistemática que se fundamenta na identificação, seleção e avaliação da qualidade de evidências (HIGGINS JPT, et al., 2011; BRASIL, 2012).

A busca foi elaborada com base na pergunta norteadora sobre "haver evidências disponíveis de tipos de intervenções farmacêuticas e seus respectivos desfechos clínicos, epidemiológicos, de acesso, humanístico e econômicos em portadores de HIV/AIDS em atendimento de média complexidade".

Para isso, montou-se uma estratégia de busca que fomentou estudos publicados nas bases Cochrane Library, Epistemonikos, Health Evidence, Health Systems Evidence, BVS (Biblioteca Virtual de Saúde) e Google Scholar; incluindo Medical Subject Headings (MeSH) e Descritores em Ciências da Saúde (DeCS).

Houve restrição de tempo, incluindo artigos publicados de 2015 a 2019, e além de restrição de idioma, preferencialmente de língua inglesa.

A busca incluiu os domínios "Pharmaceutical attention", "Pharmaceutical Care", "Pharmaceutical Interventions", "Pharmaceutical Services", "HIV/AIDS", "Medium Complexity Attention" e "Medium Complexity Care", sendo adaptada para as distintas bases eletrônicas, utilizando-se dos operadores booleanos OR e AND.

O acrônimo PICO foi utilizado para filtrar os critérios de inclusão, onde "P" é a População: maior de 18 anos e de ambos os sexos; "I" a Intervenção: Cuidado Farmacêutico; "C" o Controle: qualquer outra intervenção; "O" os Desfechos: clínicos, epidemiológicos, humanísticos, de acesso e econômicos.

A escolha dos títulos e resumos foram selecionados de forma independente pelos autores, respeitandose os critérios de inclusão (Figura 1). Os artigos de texto completo foram recuperados, os dados extraídos e a qualidade dos artigos avaliada.

O Mendeley Desktop® foi utilizado como coordenador de referências. A Plataforma Rayyan® foi empregada para reunir e selecionar os artigos. Para a preleção do fluxo de informações das diferentes fases da revisão sistemática foi utilizado o Prisma Flow Diagram ${ }^{\circledR}$. O PROGRESS ${ }^{\circledR}$ foi utilizado para identificar determinantes sociais e de equidade.

Uma planilha Exce ${ }^{\circledR}$ foi utilizada para organizar dados e informações do artigo, referentes ao Nome do artigo; Nome dos autores; Revista e ano de publicação; Objetivo do estudo; Desenho ou método do estudo; Métodos estatísticos utilizados; Tipos de intervenções avaliadas; Resultados (desfechos); Avaliação da qualidade do artigo; Identificação de Vieses; Inclusão de países de alta, média e baixa renda, em especial o Brasil; Determinantes sociais e de equidade; Conclusão e contribuição do estudo; Uso de referências atualizadas; Lacunas e limitações do estudo; Perguntas não respondidas pelos autores e Conflitos de interesse, para facilitar a síntese narrativa.

As ferramentas AMSTAR (Avaliação da Qualidade de Revisões Sistemáticas Múltiplas), AEAE (Avaliação de Estudos de Avaliação Econômica), AQET (Avaliação de Qualidade de Estudos Transversais), AECR (Avaliação de Estudo Controlado Randomizado), AQEC (Avaliação de Qualidade de Estudo de Coorte), AQRI (Avaliação de Qualidade de Revisão Sistemática) e AECNR (Avaliação de Qualidade de Estudo Controlado Não-Randomizado), foram utilizadas para a avaliação da qualidade dos estudos incluídos.

De acordo com a Resolução do CNS n 466, de 12 de dezembro de 2012, e da Resolução CNS no 510 , de 07 de abril de 2016, não foi necessário o registro no Sistema Nacional de Informação sobre Ética em Pesquisa envolvendo Seres Humanos (SISNEP) da Plataforma Brasil. 
Figura 1 - Fluxograma do processo de seleção das publicações incluídas na revisão.

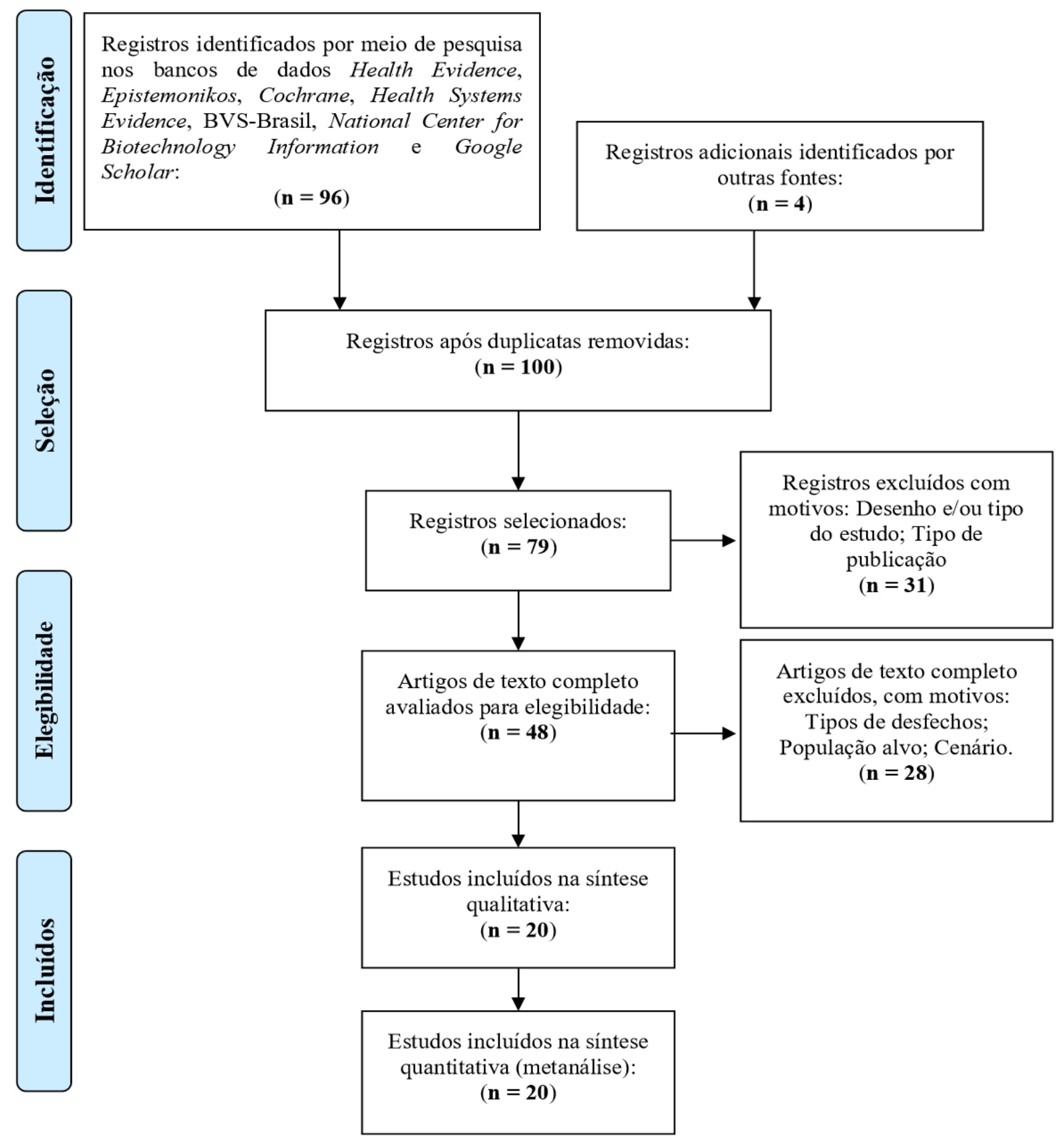

Fonte: Chaves JC, et al., 2020

\section{RESULTADOS}

Foram incluídos 20 artigos que preencheram os critérios de inclusão. Desses, 9 são estudos transversais, 2 são revisões sistemáticas, 2 são estudos clínicos randomizados, 3 são estudos de coorte, 1 é revisão integrativa, 1 é estudo clínico controlado não-randomizado e 2 são estudos de avaliação econômica. Os estudos foram realizados em países de alta, média e baixa renda, incluindo Jordânia, Brasil, Espanha, EUA, África do Sul, Tanzânia, Etiópia, África Subsaariana, Reino Unido, Canadá, Alemanha, República Popular da China, Taiwan, Holanda, Oriente Médio, África do Sul, entre outros. Foram alinhados o perfil e as características dos artigos selecionados (Quadro 1). 
Quadro 1 - Perfil e características dos artigos selecionados.

\begin{tabular}{|c|c|c|c|c|}
\hline Artigo / Qualidade & Objetivo & Método & Evidências & Conclusão \\
\hline $\begin{array}{l}\text { Tall YRA, et al. } \\
\text { (2020). } \\
\text { AQET: } 5 / 6\end{array}$ & $\begin{array}{l}\text { Explorar as barreiras e facilitadores da } \\
\text { adesão à TARV entre pacientes HIV } \\
\text { positivos na Jordânia, avaliando a } \\
\text { necessidade de serviços de assistência } \\
\text { farmacêutica. }\end{array}$ & Estudo transversal & $\begin{array}{l}\text { A presença de um farmacêutico especialista em HIV em sua } \\
\text { equipe de saúde e a implementação do Cuidado } \\
\text { Farmacêutico podem influenciar positivamente a adesão dos } \\
\text { pacientes ao tratamento. }\end{array}$ & $\begin{array}{l}\text { As intervenções incluídas sobre a implementação do Cuidado } \\
\text { Farmacêutico neste estudo demonstraram que podem melhorar } \\
\text { significativamente a adesão aos TARVs.. }\end{array}$ \\
\hline $\begin{array}{l}\text { Casagrande BJ } \\
\text { (2019). } \\
\text { AQET: } 4 / 6\end{array}$ & $\begin{array}{l}\text { Realizar } \quad 0 \quad \text { acompanhamento } \\
\text { farmacoterapêutico em pacientes em uso de } \\
\text { terapia antirretroviral. }\end{array}$ & Estudo transversal & $\begin{array}{l}\text { O acompanhamento farmacoterapêutico para pacientes em } \\
\text { uso de antirretrovirais identificou Problemas Relacionados a } \\
\text { Medicamentos, melhorando níveis de CD4+; bem como, a } \\
\text { adesão ao tratamento, evitando o desenvolvimento da Aids } \\
\text { e a necessidade de internação hospitalar. }\end{array}$ & $\begin{array}{l}\text { O farmacêutico clínico pode contribuir na identificação de erros } \\
\text { de prescrição e interações medicamentosas em prescrições } \\
\text { hospitalares contendo ARV's, auxiliando a equipe na resolução } \\
\text { de problemas relacionados à farmacoterapia. }\end{array}$ \\
\hline $\begin{array}{l}\text { Morillo-Verdugo RM, } \\
\text { et al. (2019). } \\
\text { AQET: } 4 / 6\end{array}$ & $\begin{array}{l}\text { Avaliar a influência de um programa de } \\
\text { intervenção baseado em um novo modelo } \\
\text { de cuidado para pacientes HIV+ na melhoria } \\
\text { de sua ativação com o tratamento. }\end{array}$ & Estudo transversal & $\begin{array}{l}\text { O Acompanhamento farmacoterapêutico realizado com base } \\
\text { nas necessidades dos pacientes e nos objetivos } \\
\text { farmacoterapêuticos estabelecidos, aumenta a } \\
\text { corresponsabilidade dos pacientes com seu próprio } \\
\text { tratamento por meio de informações e educação sobre o } \\
\text { autocuidado, resultando na supressão viral, mediada por } \\
\text { uma maior adesão antirretroviral. }\end{array}$ & $\begin{array}{l}\text { O programa de intervenção baseado no modelo CMO influencia } \\
\text { a ativação do paciente e pode melhorar a adesão e outros } \\
\text { resultados de saúde em pacientes HIV+. }\end{array}$ \\
\hline $\begin{array}{l}\text { Dilworth T, et al. } \\
\qquad \begin{array}{l}(2018) \\
\text { AEAE: } 25 / 28\end{array}\end{array}$ & $\begin{array}{l}\text { Determinar os efeitos clínicos e econômicos } \\
\text { da aplicação da farmácia clínica na adesão } \\
\text { ao tratamento antirretroviral em pacientes } \\
\text { que vivem com o vírus da imunodeficiência } \\
\text { humana (HIV). }\end{array}$ & $\begin{array}{l}\text { Estudo de avaliação } \\
\text { econômica }\end{array}$ & $\begin{array}{l}\text { Uma clínica multidisciplinar de adesão à TARV liderada por } \\
\text { farmacêuticos contribui e ajuda pacientes infectados pelo } \\
\text { HIV com problemas documentados de adesão à medicação } \\
\text { a alcança a supressão viral do HIV. }\end{array}$ & $\begin{array}{l}\text { Uma clínica de adesão à TARV liderada por farmacêuticos, } \\
\text { diminui a probabilidade de transmissão do HIV por esses } \\
\text { pacientes e leva a economias futuras em custos de tratamento } \\
\text { relacionados ao HIV. }\end{array}$ \\
\hline $\begin{array}{l}\text { Morillo-Verdugo RM, } \\
\text { et al. (2018). } \\
\text { AECR: } 12 / 14\end{array}$ & $\begin{array}{l}\text { Determinar a eficácia de um programa de } \\
\text { acompanhamento intensivo em cuidados } \\
\text { farmacêuticos em comparação com um } \\
\text { modelo tradicional entre pacientes } \\
\text { infectados pelo HIV com risco } \\
\text { cardiovascular moderado/alto. }\end{array}$ & $\begin{array}{l}\text { Estudos clínicos } \\
\text { randomizados }\end{array}$ & $\begin{array}{l}\text { O acompanhamento farmacoterapêuticos relacionados ao } \\
\text { risco cardiovascular promoveu a redução média do risco } \\
\text { cardiovascular absoluto, a porcentagem de pacientes que } \\
\text { atingiram a pressão arterial ideal, os níveis de lipídios no } \\
\text { sangue e os níveis de hemoglobina glicosilada e cooperou } \\
\text { para a adesão ao tratamento com HIV. }\end{array}$ & $\begin{array}{l}\text { Os cuidados farmacêuticos personalizados, baseados na } \\
\text { estratificação de riscos, nas entrevistas motivacionais e nas } \\
\text { novas tecnologias, podem levar a melhores resultados de saúde } \\
\text { em pacientes HIV+ com maior risco cardiovascular. }\end{array}$ \\
\hline $\begin{array}{l}\text { Rajesh V, et al. } \\
\text { (2018). } \\
\text { AQEC: } 5 / 6\end{array}$ & $\begin{array}{l}\text { Investigar a relação entre a qualidade de } \\
\text { vida relacionada à saúde (QVRS) e a } \\
\text { adesão à HAART ao longo do tempo. }\end{array}$ & Estudo de coorte & $\begin{array}{l}\text { A adesão à HAART é complexa e é um processo dinâmico e } \\
\text { biossocial influenciada por diversos fatores que influenciam } \\
\text { a QVRS de maneira positiva ou negativa. }\end{array}$ & $\begin{array}{l}\text { Como a HAART é um tratamento ao longo da vida, avaliar o } \\
\text { comportamento da adesão dos pacientes e melhorar a adesão } \\
\text { maximizará os benefícios da HAART e melhorará a QVRS dos } \\
\text { pacientes. Compreender as consequências sociais dessa } \\
\text { doença e fazer intervenções clínicas apropriadas também pode } \\
\text { melhorar a QVRS. }\end{array}$ \\
\hline $\begin{array}{l}\text { Domingues E, et al. } \\
\text { (2017). } \\
\text { AQEC: } 5 / 6\end{array}$ & $\begin{array}{l}\text { Avaliar o impacto dos cuidados } \\
\text { farmacêuticos no risco cardiovascular em } \\
\text { pacientes com mais de } 50 \text { anos recebendo } \\
\text { terapia antirretroviral combinada. }\end{array}$ & Estudo de coorte & $\begin{array}{l}\text { Intervenções de educação em saúde e farmacêuticas } \\
\text { ajudam na redução dos fatores de risco cardiovasculares em } \\
\text { uma única coorte de pacientes soropositivos para HIV. }\end{array}$ & $\begin{array}{l}\text { Os cuidados farmacêuticos, fornecidos como uma combinação } \\
\text { de educação em saúde e acompanhamento farmacoterapêtutico } \\
\text { para pacientes ambulatoriais em um hospital terciário, tiveram } \\
\text { um impacto positivo no risco cardiovascular em pacientes com } \\
\text { mais de } 50 \text { anos recebendo terapia antirretroviral combinada. }\end{array}$ \\
\hline $\begin{array}{l}\text { Molino C, et al. } \\
\qquad(2017) \text {. } \\
\text { AECNR: } 11 / 12\end{array}$ & $\begin{array}{l}\text { Avaliar a eficácia da intervenção } \\
\text { farmacêutica na redução de problemas } \\
\text { relacionados a medicamentos em pacientes } \\
\text { ambulatoriais com HIV / AIDS (grupo } \\
\text { intervenção) e na melhoria de parâmetros } \\
\text { llínicos no grupo intervenção em } \\
\text { comparação ao grupo controle. }\end{array}$ & $\begin{array}{l}\text { Estudos clínicos não } \\
\text { randomizados }\end{array}$ & $\begin{array}{l}\text { Foi realizada intervenção controlada com pacientes } \\
\text { pareados por sexo e contagem inicial de linfócitos T CD4 + } \\
\text { (CD4) com a análise de problemas relacionados aos } \\
\text { medicamentos (PRM) para o grupo de intervenção e } \\
\text { contagem de CD4 com a avaliação da carga viral nos dois } \\
\text { grupos. }\end{array}$ & $\begin{array}{l}\text { As consultas com o farmacêutico permitiram identificar, prevenir } \\
\text { e resolver problemas relacionados a medicamentos, } \\
\text { principalmente aqueles relacionados à segurança de } \\
\text { medicamentos. As intervenções farmacêuticas melhoraram a } \\
\text { adesão e aumentaram a eficácia da HAART, conforme sugerido } \\
\text { pela maior elevação na contagem de CD4 observada no grupo } \\
\text { de intervenção A carga viral nâo foi significativamente diferente } \\
\text { entre os valores médios final e inicial para ambos os grupos. }\end{array}$ \\
\hline
\end{tabular}




\begin{tabular}{|c|c|c|c|c|}
\hline Artigo / Qualidade & Objetivo & Método & Evidências & Conclusão \\
\hline $\begin{array}{l}\text { Nance C, et al. } \\
\qquad(2017) \text {. } \\
\text { AECR: } 12 / 13\end{array}$ & $\begin{array}{l}\text { Avaliar a eficácia de curto prazo da } \\
\text { intervenção de ACS para melhorar a } \\
\text { retenção nos cuidados e a adesão à TARV } \\
\text { para mulheres grávidas e pós-parto } \\
\text { infectadas pelo HIV durante um período de } \\
\text { estudo de } 18 \text { meses. }\end{array}$ & $\begin{array}{l}\text { Estudos clínicos não } \\
\text { randomizados }\end{array}$ & $\begin{array}{l}\text { A intervenção teve pouco ou nenhum efeito sobre a retenção } \\
\text { nos cuidados aos } 90 \text { dias pós-parto, sobre os resultados } \\
\text { secundários no ITT e análises ajustadas. No entanto, tanto } \\
\text { as análises primárias quanto as de sensibilidade por } \\
\text { fidelidade sugerem que a intervenção pode ter melhor } \\
\text { aderência à TARV pós-parto, especialmente entre mulheres } \\
\text { que vivem em áreas de influência onde a intervenção foi } \\
\text { implementada com maior intensidade. }\end{array}$ & $\begin{array}{l}\text { A intervenção baseada em ACS não teve fortes efeitos na } \\
\text { maioria dos indicadores de PTV. O envolvimento dos ACS nos } \\
\text { programas de PTV pode melhorar a adesão à TARV entre as } \\
\text { mulheres pós-parto infectadas pelo HIV, no entanto, o sucesso } \\
\text { parece fortemente dependente da implementação do programa. }\end{array}$ \\
\hline $\begin{array}{l}\text { Surur A, et al. (2017). } \\
\qquad \text { AQET: } 4 / 6\end{array}$ & $\begin{array}{l}\text { Avaliar a qualidade de vida relacionada à } \\
\text { saúde de pacientes com HIV / AIDS e a } \\
\text { associação de variáveis sociodemográficas } \\
\text { e relacionadas à doença com a qualidade } \\
\text { de vida relacionada à saúde. }\end{array}$ & Estudo transversal & $\begin{array}{l}\text { A condição atual de doença aguda dos entrevistados, não } \\
\text { mostrou associação significativa com nenhum dos domínios } \\
\text { da qualidade de vida relacionada à saúde. }\end{array}$ & $\begin{array}{l}\text { Os seis domínios da qualidade de vida relacionada à saúde } \\
\text { foram moderados. A saúde física e a espiritualidade dos dos } \\
\text { pacientes eram relativamente superiores às suas relações } \\
\text { sociais. Sexo, idade, escolaridade, residência e estado civil } \\
\text { mostraram associação significativa com pelo menos um domínio } \\
\text { da qualidade de vida relacionada à saúde. }\end{array}$ \\
\hline $\begin{array}{l}\text { Abebe T, et al. } \\
\qquad(2016) \text {. } \\
\text { AQET: } 5 / 6\end{array}$ & $\begin{array}{l}\text { Avaliar a expectativa e a satisfação de } \\
\text { pacientes com HIV / AIDS no serviço } \\
\text { farmacêutico prestado no Hospital de } \\
\text { Referência. }\end{array}$ & Estudo transversal & $\begin{array}{l}\text { Características sociodemográficas dos entrevistados, que } \\
\text { incluiu consultas sobre expectativas e satisfação com os } \\
\text { serviços farmacêuticos prestados fornecendo conselhos } \\
\text { sobre precauções e efeitos colaterais dos medicamentos } \\
\text { antirretrovirais, interações medicamentosas / alimentos, e } \\
\text { condição de armazenamento adequada. }\end{array}$ & $\begin{array}{l}\text { O nível geral de satisfação dos entrevistados com o serviço } \\
\text { farmacêutico foi baixo, enquanto a expectativa geral dos } \\
\text { entrevistados em relação aos serviços farmacêuticos foi } \\
\text { extremamente alta. O Oospital deve implementar sistemas de } \\
\text { boas práticas de dispensação em relação aos serviços e } \\
\text { desenvolvimento profissional contínuo para os profissionais, a } \\
\text { fim de melhorar a satisfação dos pacientes. }\end{array}$ \\
\hline $\begin{array}{l}\text { Ganguli A, et al. } \\
\text { (2016). } \\
\text { AMSTAR: } 11 / 11\end{array}$ & $\begin{array}{l}\text { Realizar uma revisão direcionada } \\
\text { descrevendo as condições médicas nas } \\
\text { quais os Programas de apoio ao paciente } \\
\text { (PSPs) foram implementados; ofereer } \\
\text { suporte a componentes de entrega e } \\
\text { resultados associados à implementação. }\end{array}$ & Revisão Sistemática & $\begin{array}{l}\text { Os Programas de apoio ao paciente (PSPs), incluindo } \\
\text { gerenciamento e aconselhamento de medicamentos, têm o } \\
\text { potencial de melhorar o atendimento em estados de doenças } \\
\text { crônicas com terapias complexas. Inclui clínicas } \\
\text { ambulatoriais, práticas de cuidados primários, ambientes } \\
\text { hospitalares de internação e serviços realizados na casa do } \\
\text { paciente por equipe multidisciplinar de saúde. }\end{array}$ & $\begin{array}{l}\text { A preponderância de evidências sugere um impacto positivo dos } \\
\text { PSPs na adesão, nos resultados clínicos e humanísticos. } \\
\text { Embora com menos frequência, a utilização e os custos dos } \\
\text { serviços de saúde também são reduzidos após a implementação } \\
\text { do PSP. }\end{array}$ \\
\hline $\begin{array}{l}\text { Gilbert L (2016). } \\
\qquad \text { AQET: 7/7 }\end{array}$ & $\begin{array}{l}\text { Retratar e analisar criticamente o papel } \\
\text { desempenhado pelos farmacêuticos na } \\
\text { gestão da epidemia de HIV / AIDS na África } \\
\text { do Sul. }\end{array}$ & Estudo transversal & $\begin{array}{l}\text { Credenciamento de farmacêuticos e Recursos para a AIDS, } \\
\text { para garantir ao consumidor uma alta qualidade de serviço, } \\
\text { com o credenciamento de farmácias que fornecem apoio, } \\
\text { aconselhamento e / ou outros serviços às pessoas que } \\
\text { vivem com AIDS. }\end{array}$ & $\begin{array}{l}\text { Os principais resultados indicam que os farmacêuticos não } \\
\text { abraçaram o desafio apresentado pela epidemia de HIV / AIDS } \\
\text { e, portanto, perdeu a oportunidade de desempenhar um papel } \\
\text { mais significativo na prevenção e gestão da epidemia. O acesso } \\
\text { à TARV em recursos escassos ou depende da 'troca de tarefas' } \\
\text { de médicos a outros profissionais de saúde. }\end{array}$ \\
\hline $\begin{array}{l}\text { Lima I, et al. (2016). } \\
\qquad \text { AMSTAR: } 5 / 9\end{array}$ & $\begin{array}{l}\text { Avaliar a eficácia das tecnologias da } \\
\text { informaçãoo e comunicação na adesão ao } \\
\text { tratamento antirretroviral em adultos com } \\
\text { HIV / AIDS. }\end{array}$ & Revisão Sistemática & $\begin{array}{l}\text { Intervenções destinadas a monitorar pacientes ou impedir a } \\
\text { transmissão do HIV, promovendo melhor acessibilidade e } \\
\text { qualidade dos cuidados através de ensaios clínicos com } \\
\text { base no uso de Tecnologia de Informação e Cuidado para } \\
\text { adesão ao tratamento antirretroviral por adultos com HIV / } \\
\text { AIDS }\end{array}$ & $\begin{array}{l}\text { O uso integrado das tecnologias da informação e comunicação } \\
\text { com o atendimento padrão promove maior acesso ao } \\
\text { atendimento, fortalecendo o relacionamento entre pacientes e } \\
\text { serviços de saúde, com a possibilidade de mitigar as dificuldades } \\
\text { vivenciadas pelas pessoas com HIV na obtenção de níveis } \\
\text { ótimos de adesão à terapia medicamentosa. }\end{array}$ \\
\hline
\end{tabular}




\begin{tabular}{|c|c|c|c|c|}
\hline Artigo / Qualidade & Objetivo & Método & Evidências & Conclusão \\
\hline $\begin{array}{l}\text { Oleribe O, et al. } \\
\qquad \begin{array}{l}(2016) \text {. } \\
\text { AQRI: } 6 / 8\end{array}\end{array}$ & $\begin{array}{l}\text { Discutir a necessidade de uma completa } \\
\text { disponibilização de serviços de saúde, } \\
\text { especialmente os serviços de HIVIAIDS. E, } \\
\text { discutir a lógica por trás do Modelo de } \\
\text { Socialização da EFMC e seus benefícios. }\end{array}$ & Revisão Integrativa & $\begin{array}{l}\text { A descentralização oferece aos pacientes e clientes de } \\
\text { serviços de saúde uma escolha entre diferentes níveis e } \\
\text { tipos de instituições de saúde que variam em termos de } \\
\text { níveis de sofisticação, áreas sobre as quais eles têm } \\
\text { jurisdição e o espectro de serviços disponíveis no } \\
\text { estabelecimento. Além da descentralização, os servços } \\
\text { devem ser socializados para obter uma distribuição } \\
\text { equitativa e dos serviços de saúde, bem como uma } \\
\text { cobertura universal de saúde. }\end{array}$ & $\begin{array}{l}\text { A socialização dos serviços de saúde desmistifica a noção de } \\
\text { que o atendimento ao HIV só pode ser prestado àqueles que } \\
\text { vivem nas áreas urbanas por um grupo seleto de profissionais } \\
\text { de saúde em centros de tratamento especiais. No entanto, a } \\
\text { socialização deve ir além dos serviços, cuidados e tratamento do } \\
\text { HIV; e ser aplicado a todos os segmentos de serviços de saúde. } \\
\text { Isso fortalecerá o sistema de saúde, melhorará os índices de } \\
\text { saúde, aumentará a produtividade e ajudará a alcançar as atuais } \\
\text { metas de desenvolvimento do milênio (ODMs) as metas } \\
\text { propostas de desenvolvimento sustentável (ODS). }\end{array}$ \\
\hline $\begin{array}{l}\text { Cope } R \text {, et al. (2015). } \\
\qquad \text { AQEC: } 6 / 6\end{array}$ & $\begin{array}{l}\text { Avaliar se o impacto da inclusão de um } \\
\text { farmacêutico clínico no time interdisciplinar } \\
\text { para o tratamento de pacientes com HIV } \\
\text { melhora os resultados para estados de } \\
\text { doenças crônicas, além do HIV. }\end{array}$ & Estudo de coorte & $\begin{array}{l}\text { A integração do farmacêutico clínico no grupo interdisciplinar } \\
\text { de acompanhamento aos pacientes HIV promoveu } \\
\text { alterações desde a linha de base ao longo de } 18 \text { meses de } \\
\text { HbA1c, lipoproteína de baixa densidade (LDL) e pressão } \\
\text { arterial, respectivamente. Além de evidenciar número de } \\
\text { interações medicamentosas, carga viral do HIV, contagem } \\
\text { de CD4, alteração percentual no status de fumantes e } \\
\text { percentual de pacientes tratados com recomendações de } \\
\text { diretrizes cardiovasculares. }\end{array}$ & $\begin{array}{l}\text { O envolvimento do farmacêutico em uma clínica de atenção } \\
\text { primária ao HIV parece resultar em mais manejo adequado de } \\
\text { comorbidades crônicas de maneira custo-efetiva, embora } \\
\text { resultados positivos a longo prazo podem ser difíceis de } \\
\text { estabelecer em um ambiente urbano da população. Acreditamos } \\
\text { que esses dados apoiam a expansão do envolvimento do } \\
\text { farmacêutico nos centros de atenção primária ao HIV para } \\
\text { estabelecer modelos práticas melhores para as equipes } \\
\text { interdisciplinares padrão. }\end{array}$ \\
\hline $\begin{array}{l}\text { Duncombe CBA, et } \\
\text { al. (2015). } \\
\text { AQET: } 5 / 7\end{array}$ & $\begin{array}{l}\text { Promover programas de HIV para expandir } \\
\text { a elegibilidade ao tratamento, para que } \\
\text { muitas pessoas que entram nos cuidados } \\
\text { não serem 'pacientes', mas membros } \\
\text { saudáaveis, ativos e produtivos da } \\
\text { sociedade. }\end{array}$ & Estudo de transversal & $\begin{array}{l}\text { Reformular os cuidados com o HIV, colocando as pessoas } \\
\text { no centro da administração antirretroviral. }\end{array}$ & $\begin{array}{l}\text { A estrutura proposta pelo estudo pode orientar os formuladores } \\
\text { de políticas a introduzir e ampliar novas abordagens para a } \\
\text { prestação de serviços em toda a cascata de atendimento ao HIV. } \\
\text { Os órgãos normativos e os implementadores líderes devem } \\
\text { continuar a desenvolver kits de ferramentas e diretrizes para } \\
\text { ajudar países e fornecedores a implementar essas abordagens. }\end{array}$ \\
\hline $\begin{array}{l}\text { Fokam J, et al. } \\
\qquad \begin{array}{l}(2015) \text {. } \\
\text { AQET: } 5 / 7\end{array}\end{array}$ & $\begin{array}{l}\text { Avaliar a viabilidade dos novos EEls, } \\
\text { através de um estudo piloto, para } \\
\text { planejamento estratégico, monitoramento e } \\
\text { avaliação do programa nacional de TARV. }\end{array}$ & Estudo transversal & $\begin{array}{l}\text { O Monitoramento dos indicadores de alerta precoce da } \\
\text { resistência aos medicamentos para HIV com identificação } \\
\text { clínicas e fatores programáticos com desempenho abaixo do } \\
\text { ideal. }\end{array}$ & $\begin{array}{l}\text { A demora na coleta dos medicamentos e o esgotamento nas } \\
\text { farmácias são os principais fatores que favorecem a emergência } \\
\text { do HIVDRR, com riscos mais altos nas áreas rurais e na atenção } \\
\text { primária à saúde. A retenção nos cuidados parece aceitável em } \\
\text { geral, enquanto as práticas de dispensação de TARV são } \\
\text { padrão. }\end{array}$ \\
\hline $\begin{array}{l}\text { Sherestha R, et al. } \\
\qquad(2015) \text {. } \\
\text { AECCR: } 14 / 14\end{array}$ & $\begin{array}{l}\text { Fornecer uma descrição passo a passo do } \\
\text { desenvolvimento e adaptação da } \\
\text { intervenção } 3 \mathrm{H}+\text {; o desenho experimental } \\
\text { comparativo inovador de não inferioridade } \\
\text { para testar a intervenção } 3 \mathrm{H}+\text { com o } \\
\text { 'padrão-ouro'; e, evidências empíricas a } \\
\text { partir de uma análise formal de custo- } \\
\text { efetividade que o justifique + quando } \\
\text { comparado ao HHRP + original. }\end{array}$ & $\begin{array}{l}\text { Estudo clínico controlado } \\
\text { randomizado }\end{array}$ & $\begin{array}{l}\text { Compara a intervenção abreviada de } 3 \mathrm{H}+\text { com o HHRP + } \\
\text { existente, o padrão-ouro para prevenção secundária de HIV } \\
\text { para PWUDs infectados por HIV. }\end{array}$ & $\begin{array}{l}\text { Em geral, os resultados apontam para os potenciais benefícios } \\
\text { de } 3 \mathrm{H}+\text { em toda a população como uma alternativa mais } \\
\text { econômica ao HHRP + quando usado em conjunto com a terapia } \\
\text { de reposição de opióides em um contexto clínico. }\end{array}$ \\
\hline $\begin{array}{l}\text { Syed I, et al. (2015) } \\
\qquad \text { AQET: } 6 / 7\end{array}$ & $\begin{array}{l}\text { Explorar as perspectivas da doença de } \\
\text { pacientes da Malásia com HIV / AIDS, que, } \\
\text { até onde sabemos, nunca foram } \\
\text { investigados antes da polifarmácia em } \\
\text { idosos. }\end{array}$ & $\begin{array}{c}\text { Estudo Transversal } \\
\text { Qualitativo }\end{array}$ & $\begin{array}{l}\text { Intervenções educacionais, especialmente para os } \\
\text { adolescentes, para minimizar os comportamentos arriscados } \\
\text { do HIV. }\end{array}$ & $\begin{array}{l}\text { Os resultados forneceram informações básicas sobre as } \\
\text { percepções dos pacientes em relação à divulgação de doenças } \\
\text { e status entre os pacientes com HIV / AIDS, o que pode ajudar } \\
\text { para melhorar a conscientização e aceitação da doença. }\end{array}$ \\
\hline
\end{tabular}

Legenda: AMSTAR: Avaliação da Qualidade de Revisões Sistemáticas Múltiplas; AEAE: Avaliação de Estudos de Avaliação Econômica; AQET: Avaliação de Qualidade de Estudos Transversais; AECR: Avaliação de Estudo Controlado Randomizado; AQEC: Avaliação de Qualidade de Estudo de Coorte; AQRI: Avaliação de Qualidade de Revisão Sistemática; AECNR: Avaliação de Qualidade de Estudo Controlado Não-Randomizado. Fonte: Chaves JC, et al., 2020. 


\section{Síntese das evidências sobre intervenções relacionadas a desfechos clínicos}

As evidências das categorias de intervenções encontradas foram: profissionais, organizacionais, governamentais, financeiras e multifacetadas. Essas intervenções apresentaram como principais desfechos clínicos: a redução da prescrição de medicamentos potencialmente inapropriados, a melhoria do uso de medicamentos apropriados e seguros, a melhoria da adesão, a redução de eventos adversos a medicamentos, as reações adversas a medicamentos, as interações medicamentos-medicamentos e os resultados negativos de saúde associados a medicamentos para os desfechos clínicos (Tabela 1).

\section{Intervenções profissionais}

Os trabalhos incluídos na presente revisão analisaram uma ou mais intervenções farmacêuticas a profissionais, podendo ser direcionadas ao prescritor, ao usuário ou ao cuidador. Além disso, avaliaram essas intervenções sobre um ou mais desfechos, como resultados sobre a redução de medicamentos potencialmente inapropriados, a adesão ao tratamento, reações adversas e interações medicamentosas.

$\mathrm{Na}$ avaliação sobre as intervenções educativas direcionadas aos usuários e/ou cuidadores, Domingues $\mathrm{E}$, et al. (2017) registraram que estas proporcionam redução de reações adversas a medicamentos, enquanto que Morillo-Verdugo RM, et al. (2019) e Duncombe CBA, et al. (2015) relataram redução de resultados negativos de saúde associados a medicamentos e Syed, et al. (2015), melhora do uso de medicamentos apropriados e seguros.

Muitos estudos registram que as intervenções educativas melhoraram a adesão ao tratamento (TALL YRA, et al., 2020; MORILLO-VERDUGO RM, et al., 2019; DOMINGUES E, et al., 2017; MOLINO C, et al., 2017; SURUR A, et al., 2017; DUNCOMBE CBA, et al., 2015).

Sobre as intervenções direcionadas aos prescritores, Casagrande BJ (2019) registra que essas intervenções promovem a melhora da adesão ao tratamento, a redução de prescrições de medicamentos potencialmente inadequados e a redução de interações medicamentosas, ocorrendo através da análise de uso de medicamentos prescritos. Enquanto Domingues E, et al. (2017) registram redução de reações adversas a medicamentos.

Ainda relacionado às intervenções direcionadas ao prescritor, há registros de que quando realizadas por meio da análise e/ou avaliação de caso clínico, há melhora da adesão ao tratamento (NANCE C, et al., 2017).

\section{Intervenções Organizacionais}

Sobre as intervenções farmacêuticas organizacionais, os artigos avaliaram tanto o impacto das Tecnologias de Informação, quanto do Cuidado Farmacêutico.

$\mathrm{Na}$ avaliação das intervenções utilizando Tecnologia da Informação em relação à melhoria da adesão ao tratamento, Duncombe CBA, et al. (2015) registram melhora com o uso de sistemas de suporte à decisão clínica, enquanto Rajeshr V, et al. (2018) avaliaram essa melhora com ferramentas de triagem de risco.

Já no que se refere ao Cuidado Farmacêutico, foi avaliado um ou mais desfechos relacionados à utilização de medicamentos inapropriados, à adesão ao tratamento, assim como à ocorrência de reações adversas a medicamentos, interações medicamentosas e resultados negativos relacionados a medicamentos. MorilloVerdugo RM, et al. (2018) e Domingues E, et al. (2017) registram melhoria do uso de medicamentos seguros e apropriados, tendo o segundo artigo também apresentado redução da prescrição de medicamentos potencialmente inapropriados.

Na avaliação dos autores Tall YRA, et al. (2020), Dilworth T, et al. (2018), Morillo-Verdugo RM, et al. (2018), Domingues E, et al. (2017), Molino C, et al. (2017) e Abebe T, et al. (2016) registraram melhora da adesão ao tratamento, enquanto que Abebe $T$ et al. (2016) registram redução de Reações Adversas a Medicamentos.

Por fim, Molino C, et al. (2017), Abebe T, et al. (2016) e Cope R, et al. (2015) registram redução de interações medicamentos-medicamentos, enquanto Morillo-Verdugo RM et al, 2018, Molino C, et al. (2017) e Cope $R$, et al. (2015) verificaram redução de resultados negativos de saúde associados a medicamentos.

\section{Intervenções financeiras}

Em relação à avaliação das intervenções farmacêuticas financeiras, Fokam J, et al. (2015) registram que estas reduzem a prescrição de medicamentos potencialmente inapropriados, enquanto Dilworth $\mathrm{T}$, et al. 
(2018), Gilbert L (2016) e Sherestha R, et al. (2015) relatam melhora na adesão ao tratamento, o que leva uma melhoria de qualidade de saúde e consequentemente em menos gastos com internações, consultas e comorbidades. Ainda sobre essa análise, Gilbert L (2016) e Fokam J, et al. (2015) corroboram com Dilworth T, et al. (2018), Gilbert L (2016) e Sherestha R, et al. (2015) indicando que a intervenção financeira reduz resultados negativos de saúde associados a medicamentos.

\section{Intervenções Governamentais}

Oleribe O, et al. (2016) registraram intervenções governamentais que promovem uma descentralização dos serviços de saúde, com a inclusão do profissional farmacêutico na equipe multiprofissional que fornece níveis específicos de atendimento a indivíduos infectados pelo HIV. Essas intervenções proporcionaram a redução de prescrição de medicamentos potencialmente inapropriados e a redução de resultados negativos de saúde associados a medicamentos.

\section{Intervenções multifacetadas}

As intervenções multifacetadas registradas por Syed I, et al. (2015) exploraram as crenças e o entendimento dos pacientes com HIV/Aids, compreendendo o conhecimento e a crença dos pacientes em relação à doença, desempenhando uma redução na prescrição de medicamentos potencialmente inapropriados; neste contexto, o farmacêutico tem um papel essencial no empoderamento direcionado ao paciente.

\section{Síntese das evidências sobre intervenções relacionadas a desfechos epidemiológicos, humanísticos, econômicos e de acesso a serviços.}

A Tabela 2 ilustra os indicativos das categorias de intervenções, evidenciando as intervenções profissionais, organizacionais, governamentais, financeiras e multifacetadas. Em relação aos desfechos, foram apresentados: desfechos de acesso ao serviço (redução de consultas ambulatoriais, de visitas domiciliares, de visitas aos serviços de urgência e emergência, de internações hospitalares, de tempo de internação hospitalar), epidemiológicos (morbidade e mortalidade), humanísticos (melhoria do estado de saúde, melhoria da qualidade de vida relacionada à saúde), e econômicos (redução de custos de medicamentos).

\section{Intervenções Profissionais}

As intervenções profissionais, realizadas por farmacêuticos, foram direcionadas principalmente aos prescritores por meio da análise e/ou avaliação de caso clínico e por meio da revisão da utilização de medicamentos. Após as intervenções, foram analisados os desfechos clínicos e desfechos substitutos. Em relação às intervenções aos prescritores, Gilbert $L$ (2016) avaliaram as mesmas quando realizadas por meio da análise e/ou avaliação de caso clínico, enquanto Casagrande BJ (2019) avaliaram por meio da revisão da utilização de medicamentos, tendo ambos registrado melhora no desfecho clínico e substituto. Já Tall YRA, et al. (2020) registram que intervenções educativas direcionadas aos usuários e/ou cuidadores também proporciona a melhoria no estado de saúde do paciente em relação aos desfechos analisados.

\section{Intervenções Organizacionais}

Quanto às intervenções organizacionais, os trabalhos avaliaram sobretudo as utilizando Tecnologia da Informação ou o cuidado farmacêutico. No que se refere aos que avaliaram a Tecnologia de Informação, Lima I, et al. (2016) registram que estas intervenções, por meio do Serviços de Informações sobre Medicamentos, proporciona a redução de consultas ambulatoriais, enquanto Duncombe CBA, et al. (2015), avaliando a intervenção pelo uso de ferramentas de triagem de risco, relatou melhoria da qualidade de vida do paciente.

Já na avalição da intervenção por meio do cuidado farmacêutico, Ganguli A, et al. (2016) relataram redução do tempo de internação hospitalar, enquanto Domingues E, et al. (2017) e Molino C, et al. (2017), melhoria da qualidade de vida, e Surur A, et al. (2017) e Ganguli A, et al. (2016), redução de custos de medicamentos.

\section{Determinantes sociais e de equidade}

Quanto aos determinantes sociais e de equidade, foram observados que os principais parâmetros abordados foram relativos ao local de residência, porém, não foram mencionados a relatividade entre zona urbana ou zana rural. Outros dados predominantes foram em relação à raça/etnia/cultura/idioma e sexo/gênero (Tabela 3). Desse modo, em geral, os estudos incluídos não apresentaram a análise de subgrupos quanto aos determinantes sociais e equidade. 
Tabela 1 - Intervenções e evidências de desfechos clínicos.

\begin{tabular}{|c|c|c|c|c|c|c|c|c|c|}
\hline \multirow{3}{*}{\multicolumn{3}{|c|}{ INTERVENÇÕES }} & \multicolumn{7}{|c|}{ DESFECHOS CLÍNICOS } \\
\hline & & & \multicolumn{2}{|c|}{$\begin{array}{l}\text { Polifarmácia: Erros de } \\
\text { Medicação }\end{array}$} & \multirow{2}{*}{$\begin{array}{c}\text { Adesão } \\
\text { Melhora da } \\
\text { Adesão }\end{array}$} & \multicolumn{4}{|c|}{ Problemas Relacionados aos Medicamentos } \\
\hline & & & $\begin{array}{c}\text { Redução da } \\
\text { Prescrição de } \\
\text { MPP* }^{*}\end{array}$ & $\begin{array}{l}\text { Melhora do } \\
\text { Uso de } \\
\text { MAS }^{* *}\end{array}$ & & $\begin{array}{l}\text { Redução } \\
\text { de } \text { EAM }^{\star * *}\end{array}$ & $\begin{array}{l}\text { Redução de } \\
\text { RAM+ }\end{array}$ & $\begin{array}{l}\text { Redução de } \\
\text { IMM++ }\end{array}$ & $\begin{array}{l}\text { Redução de } \\
\text { RNSAM+++ }\end{array}$ \\
\hline \multirow{4}{*}{ 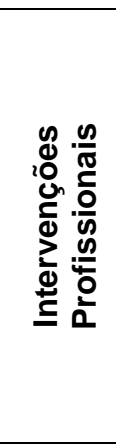 } & \multirow{3}{*}{ Prescritores \pm} & $\begin{array}{l}\text { Análise e/ou Avaliação } \\
\text { de Caso Clínico }\end{array}$ & * & * & (22) & * & * & * & * \\
\hline & & $\begin{array}{l}\text { Revisão da Utilização } \\
\text { de Medicamentos }\end{array}$ & (15) & * & (15) & * & (20) & (15) & * \\
\hline & & $\begin{array}{c}\text { Intervenções } \\
\text { Educativas para os } \\
\text { Prescritores }\end{array}$ & * & * & * & * & * & * & * \\
\hline & $\begin{array}{c}\text { Usuários e } \\
\text { cuidadores } \pm \pm\end{array}$ & $\begin{array}{c}\text { Intervenções } \\
\text { Educativas para os } \\
\text { Usuários e/ou } \\
\text { Cuidadores }\end{array}$ & * & (33) & $\begin{array}{l}(14)(16)(20) \\
(21)(23)(30)\end{array}$ & * & (20) & * & $(16)(30)$ \\
\hline \multirow{6}{*}{ 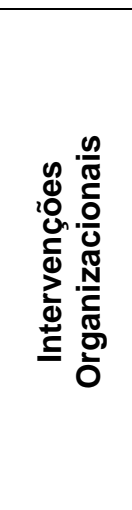 } & \multirow{4}{*}{$\begin{array}{c}\mathrm{TI}+ \\
\text { Comunicação }\end{array}$} & $\begin{array}{c}\text { Busca Ativa de Dados } \\
\text { e Informações do } \\
\text { Utente }\end{array}$ & * & * & * & * & * & * & * \\
\hline & & $\begin{array}{c}\text { Serviços de } \\
\text { Informações sobre } \\
\text { Medicamentos }\end{array}$ & * & & * & * & * & * & * \\
\hline & & $\begin{array}{l}\text { Sistemas de Suporte à } \\
\text { Decisão Clínica }\end{array}$ & * & * & (30) & * & * & * & * \\
\hline & & $\begin{array}{l}\text { Uso de Ferramentas } \\
\text { de Triagem de Risco }\end{array}$ & * & * & (19) & * & * & * & * \\
\hline & \multicolumn{2}{|c|}{ Cuidado Farmacêutico } & (20) & $(18)(20)$ & $\begin{array}{l}\text { (14) (17) (18) } \\
(20)(21)(24)\end{array}$ & * & (24) & (21) (24) (29) & (18) (21) (29) \\
\hline & \multicolumn{2}{|c|}{ Gestão Técnica de Medicamentos† } & * & * & * & * & * & * & * \\
\hline \multirow{2}{*}{\multicolumn{3}{|c|}{ Intervenções Financeiras $\dagger \dagger$}} & (31) & * & $(17)(26)(32)$ & * & * & * & (26) (31) \\
\hline & & & (28) & * & * & * & * & * & (28) \\
\hline \multicolumn{3}{|c|}{ Intervenções multifacetadas } & (33) & * & * & * & * & ${ }^{*}$ & * \\
\hline
\end{tabular}


Tabela 2 - Intervenções e as evidências de desfechos de acesso aos serviços, epidemiológicos, humanísticos e econômicos.

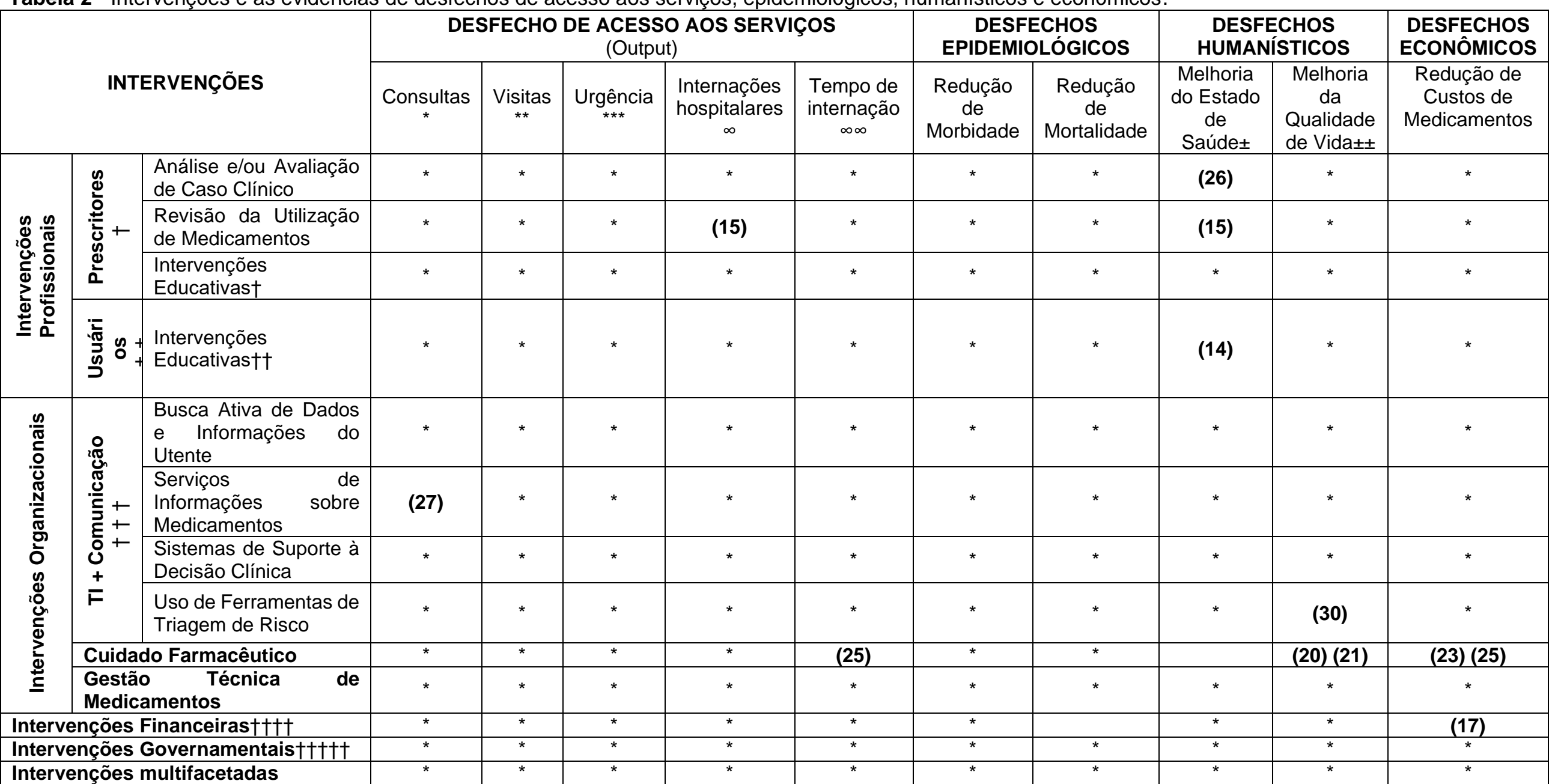

Legenda: ()$=$ Referências e suas evidências. $(-)=$ Não foi estudado e/ou não há evidências. * ${ }^{*}$ Redução de Consultas ambulatoriais. ${ }^{* *}=$ Redução de visitas

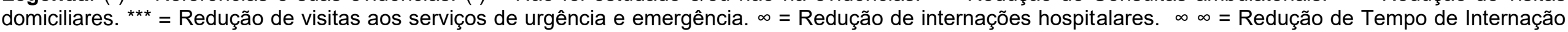
Hospitalar. $\pm=E m$ relação aos desfechos clínicos e desfechos substitutos. $\pm \pm=$ Relacionada à Saúde HRQoL. $\dagger=$ Direcionadas aos prescritores. $\dagger \dagger=$ Direcionadas aos usuários e/ou cuidadores. †t† = Tecnologia da informação + comunicação. t†t† = Programas de incentivo para mudanças na prática da prescrição. †t†t† = Intervenções Regulatórias: políticas governamentais que regulam a prescrição. Fonte: Chaves JC, et al., 2020. 
Tabela 3 - Determinantes sociais e de equidade.

\begin{tabular}{|c|c|c|c|c|c|c|c|c|}
\hline \multirow{2}{*}{ ARTIGO } & \multicolumn{8}{|c|}{ EQUIDADE: Abordagens e relatos de questões de equidade } \\
\hline & $\mathbf{P}$ & $\mathbf{R}$ & 0 & $\mathbf{G}$ & $\mathbf{R}$ & $\mathbf{E}$ & $\mathbf{S}$ & $\mathbf{S}$ \\
\hline Tall YRA, et al. (2020) & $(+)$ & * & $(-)$ & $9 \hat{0}$ & $(-)$ & ** & $(-)$ & - \\
\hline Casagrande BJ, (2019) & $(+)$ & $(-)$ & $(-)$ & 90 & $(-)$ & $(-)$ & $(-)$ & - \\
\hline Morillo-Verdugo RM, et al. (2019) & $(+)$ & $(-)$ & $(-)$ & 90 & $(-)$ & $(-)$ & $(-)$ & - \\
\hline Dilworth T, et al. (2018) & $(+)$ & $(-)$ & $(-)$ & 90 & $(-)$ & $(-)$ & $(-)$ & - \\
\hline Morillo-Verdugo RM, et al. (2018) & $(+)$ & $* * * *$ & $(-)$ & $q 0^{\lambda}$ & $(-)$ & $(-)$ & $(-)$ & - \\
\hline Rajeshr V, et al. (2018) & $(+)$ & $(-)$ & $(-)$ & q0 & $(-)$ & $(-)$ & $(-)$ & - \\
\hline Domingues E, et al. (2017) & $(+)$ & $(-)$ & $(-)$ & $q 0$ & $(-)$ & $(-)$ & $(-)$ & - \\
\hline Molino C, et al. (2017) & $(+)$ & $(-)$ & $(-)$ & $q 0^{\lambda}$ & $(-)$ & $(-)$ & $(-)$ & - \\
\hline Nance C, et al. (2017) & $(+)$ & $(-)$ & $(-)$ & $q$ & $(-)$ & $(-)$ & $(-)$ & - \\
\hline Surur A, et al. (2017) & $(+)$ & $* * * *$ & $(-)$ & q0 & $(-)$ & $(-)$ & $(-)$ & - \\
\hline Abebe T, et al. (2016) & $(+)$ & $* * * *$ & $(-)$ & q0 & $(-)$ & $(-)$ & $(-)$ & - \\
\hline Gangul A, et al. (2016) & $(+)$ & $* * * *$ & $(-)$ & q0 & $(-)$ & $(-)$ & $* * *$ & - \\
\hline Gilbert L. (2016) & $(+)$ & $* * \star \star$ & $(-)$ & $q \hat{0}$ & $(-)$ & $(-)$ & $(-)$ & - \\
\hline Lima I, et al. (2016) & $(+)$ & $(-)$ & $(-)$ & $q 0^{\lambda}$ & $(-)$ & $(-)$ & $(-)$ & - \\
\hline Oleribe O, et al. (2016) & $(+)$ & 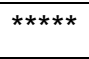 & $(-)$ & q0 & $(-)$ & $(-)$ & $(-)$ & - \\
\hline Cope R, et al. (2015) & $(+)$ & $(-)$ & $(-)$ & क्री & $(-)$ & $(-)$ & $* * *$ & - \\
\hline Duncombe CBA, et al. (2015) & $(+)$ & $(-)$ & $(-)$ & क्र & $(-)$ & $(-)$ & $(-)$ & - \\
\hline Fokam J, et al. (2015) & $(+)$ & $\overline{* \star \star * \star \star \star ~}$ & $(-)$ & क्र & $(-)$ & $(-)$ & $(-)$ & - \\
\hline Sherestha R, et al. (2015) & $(+)$ & 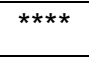 & $(-)$ & क्र & $(-)$ & $(-)$ & $(-)$ & - \\
\hline Syed I, et al. (2015) & $(+)$ & $(-)$ & $(-)$ & की & $(-)$ & $(-)$ & $(-)$ & - \\
\hline
\end{tabular}

Legenda: $\mathrm{P}=$ Local de residência; $\mathrm{R}=$ Raça/etnia/cultura/idioma; $\mathrm{O}=$ Ocupação; $\mathrm{G}=$ Sexo/gênero; $\mathrm{R}=$ Religião; $\mathrm{E}$ = Educação; $\mathrm{S}$ = Estado socioeconômico; $\mathrm{S}$ = Capital social. $(+)$ = País de alta, média e baixa renda, sem mencionar se vivem em zona urbana ou rural. ( - ) = Sem informação. $\hat{O}=$ masculino; $q$ = feminino. ${ }^{*}=$ Cidadãos Jordanianos, ${ }^{* *}=$ Educação formal, ${ }^{* * *}=$ Empregados/desempregados ${ }^{* * * *}=$ Inglês e Outros idiomas; ${ }^{* * * *}=$ Inglês. Fonte: Chaves JC, et al., 2020.

\section{DISCUSSÃO}

Com o surgimento da terapia antirretroviral de alta eficácia (HAART), que propõem um tratamento com objetivo na melhoria da qualidade de vida, começou-se a observar maior necessidade de transpor as barreiras que diminuiriam a adesão ao tratamento em pacientes com HIV (RAJESH V, et al., 2019). Essas barreiras incluem estigmatização, medo da divulgação, forma de dosagem do medicamento, eventos adversos e pouca cooperação dos profissionais de saúde.

Para isso, os fatores de apoio ao tratamento dos portadores de HIV incluíam o apoio da família e dos amigos, lembretes móveis eletrônicos, sentimento de responsabilidade por criar filhos e melhorar o uso da terapia antirretroviral (TARV) (TALL YRA, et al., 2020).

Uma forma de intervir na quebra dessas barreiras, para obtenção de um resultado positivo é aumentar a corresponsabilidade dos pacientes com seu próprio tratamento por meio de informações e educação sobre o autocuidado (MORILLO-VERDUGO RM, et al., 2018).

As intervenções farmacêuticas têm sido muito utilizadas após a detecção de problemas associados à prescrição da TARV, comprovando a necessidade de um projeto de acompanhamento farmacoterapêutico para pacientes em uso desses medicamentos (CASAGRANDE BJ, 2019).

Desse modo, é prevista a necessidade de um farmacêutico em sua equipe de saúde para prestar serviços de assistência farmacêutica especializados, o que pode melhorar os parâmetros clínicos e de qualidade de vida, reforçada pelo aumento da adesão dos pacientes, corroborando com a efetividade dos HAART (MOLINO C, et al., 2017). 
A melhora nos desfechos clínicos, epidemiológicos, de acesso, humanístico e econômicos em portadores de HIV/AIDS, são observados nas intervenções de cuidado farmacêutico por meio da equipe multidisciplinar de saúde (CASAGRANDE BJ, 2019; MORILLO-VERDUGO RM, et al., 2018; DILWORTH T, et al., 2018; MOLINO C, et al., 2017; SURUR A, et al., 2017; SHRESTHA R, et al., 2015).

Além dos efeitos positivos da resolução e prevenção dos Problemas Relacionados aos Medicamentos, é observado melhora nos parâmetros clínicos de níveis de Carga Viral (CV) e contagem de linfócitos T CD4+ (CD4), assim como redução de riscos nas comorbidades crônica, além do HIV; podendo configurar essas intervenções também como altamente econômicas, já que os gastos com internações e polifarmácia são diminuídos (DILWORTH T, et al., 2018; SHRESTHA R, et al., 2015).

Por fim, as intervenções de educação em saúde e acompanhamento farmacoterapêutico tem também um impacto positivo no risco cardiovascular em pacientes em terapia antirretroviral combinada, além da redução de parâmetros clínicos de outras doenças crônicas (melhora na hipertensão arterial, glicemia, entre outros), tabagismo e obesidade (DOMINGUES E, et al., 2017). Outrossim, além da intervenção farmacêutica, o uso integrado de tecnologias da informação e comunicação, em conjunto com o atendimento convencional, promove melhor acesso ao atendimento, fortalecendo o relacionamento entre pacientes e serviços de saúde, possibilitando mitigar as dificuldades vivenciadas pelas pessoas com HIV/Aids e a obtenção de melhores grau de adesão à terapia medicamentosa (LIMA I, et al., 2016).

Quanto as implicações para a pesquisa, observa-se que há limitada literatura evidenciando tipos de intervenções e seus respectivos desfechos clínicos, epidemiológicos, de acesso, humanístico e econômicos em portadores de HIV/AIDS em atendimento de média complexidade.

Destaca-se que há perguntas que ainda permanecem não respondidas; ou seja, a contribuição do Cuidado Farmacêutico quanto à redução de Eventos Adversos a Medicamentos, bem como aqueles relacionados ao custo-efetividade, custo-benefício e custo utilidade, entre outros.

Precisa-se de evidências robustas para as categorias de intervenções farmacêuticas nos campos profissionais, organizacionais, regulatórios, financeiros e multifacetados quanto à efetividade e eficiência do Cuidado Farmacêutico em portadores de HIV/Aids em atendimento de média complexidade. Nas implicações para as políticas e programas, há evidências de que as políticas e programas relacionados ao Cuidado Farmacêutico para portadores de HIV/Aids, por meio de intervenções efetivas e eficientes, contribuem para a sua segurança e melhoria da qualidade de vida.

Registra-se como limitação o fato de que nem sempre as intervenções e os desfechos avaliados eram os mesmos, dificultando a avaliação de algumas intervenções por todos os autores. Além disso, a qualidade das evidências apresentadas e, em alguns casos, a ausência de registros de conflitos éticos também se apresentam como limitações. Por fim, há a possibilidade de não se ter incluído estudos potencialmente elegíveis devido às distintas sinonímias dos descritores e/ou palavras-chave.

\section{CONSIDERAÇÕES FINAIS}

Observa-se que o cuidado farmacêutico, por meio de intervenções organizacionais, profissionais, financeiras, governamentais e multifacetadas, contribui para a melhoria de desfechos clínicos, epidemiológicos, humanísticos, econômicos e de acesso e equidade. Além de fortalecer as estratégias do uso racional de medicamentos e promover uma melhor qualidade de vida. Quanto à aplicação dessas intervenções farmacêuticas, direcionadas aos pacientes soropositivos para HIV, pode-se observar não apenas a melhora na adesão dos pacientes ao tratamento com antirretrovirais, como também, a melhora na qualidade de vida e morbidade, fortalecendo a importância do profissional farmacêutico nesse campo de média complexidade.

\section{REFERENCIAS}

1. ABEBE T, et al. Expectation and satisfaction of HIV/AIDS patients toward the pharmaceutical care provided at Gondar university referral hospital, northwestern Ethiopia: A cross-sectional study. Patient Preference and Adherence, 2016; 10: 2073-2082.

2. ABRÃO FMS, et al. Características Estruturais e Organizacionais de Serviços de Assistência Especializada em Hiv/Aids na Cidade de Recife, Brasil. Revista Baiana de Saúde Pública, 2014; 38(1): 140-154. 
3. BENZAKEN A. In: As conquistas e desafios no enfrentamento ao HIV/Aids no Brasil (Painel). $15^{\text {a }}$ Expoepi: 27 de junho de 2017. Brasília. Distrito Federal.

4. BRASIL. Ministério da Saúde. Departamento de Vigilância, Prevenção e Controle das IST, Aids e Hepatites Virais. Nota Informativa ํㅡ 03/2018, de 10 de abril de 2018. Apresenta as recomendações de substituição (switch) de esquemas de terapia antirretroviral contendo ITRNN ou IP/r por dolutegravir, para pessoas vivendo com HIV com supressão viral maiores de 12 anos de idade. 2018. Brasília. Distrito Federal, 6p.

5. BRASIL. Ministério da Saúde. Secretaria de Vigilância em Saúde, Departamento de DST, Aids e Hepatites Virais. Protocolo clínico e diretrizes terapêuticas para manejo da infecção pelo HIV em adultos. 2018. Brasília. Distrito Federal, $416 \mathrm{p}$

6. BRASIL. Ministério da Saúde. Secretaria de Ciência, Tecnologia e Insumos Estratégicos. Departamento de Ciência e Tecnologia. Diretrizes metodológicas: elaboração de revisão sistemática e metanálise de ensaios clínicos randomizados. Brasília: Editora do Ministério da Saúde, 2012. 92 p.: il. - (Série A: Normas e Manuais Técnicos).

7. BRASIL. Congresso Nacional. Lei no 9.313, de 13 de novembro de 1996. Dispõe sobre a distribuição gratuita de medicamentos aos portadores do HIV e doentes de AIDS. DOU de 14.11.1996. Brasília. Distrito Federal.

8. CASAGRANDE BJ. O farmacêutico clínico e o cuidado de pacientes HIV+ no ambiente hospitalar. Dissertação (Mestrado Profissional em Farmacologia) - Centro de Ciências Biolóficas, Universidade Federal de Santa Catarina, Florianópolis, 2019; 83p.

9. COPE R, et al. Evaluating the effects of an interdisciplinary practice model with pharmacist collaboration on HIV patient co-morbidities. AIDS Patient Care and STDs, 2015; 29(8): 445-453.

10. DILWORTH T, et al. Clinical and economic effects of a pharmacist-administered antiretroviral therapy adherence clinic for patients living with HIV. Journal of Managed Care and Specialty Pharmacy, 2018; 24(2): 165-172.

11. DOMINGUES E, et al. Impact of pharmaceutical care on cardiovascular risk among older HIV patients on antiretroviral therapy. International Journal of Clinical Pharmacy, 2017; 39(1): 52-60.

12. DUNCOMBE C, et al. Reframing HIV care: Putting people at the centre of antiretroviral delivery. Tropical Medicine and International Health Publisher: Blackwell Publishing Ltd, 2015; 20(4): 430-447.

13. DUNCOMBE CBA, et al. Treatment 2.0: catalyzing the next phase of treatment, care, and support. Curr Opin HIV AIDS, 2013; 8(1): 4-11.

14. FOKAM J, et al. Monitoring HIV drug resistance early warning indicators in Cameroon: A study following the revised world health organization recommendations. PLoS ONE, 2015; 10(6).

15. GANGULI A, et al. The impact of patient support programs on adherence, clinical, humanistic, and economic patient outcomes: A targeted systematic review. Patient Preference and AdherencePublisher: Dove Medical Press Ltd. 2016; 10: 711-725.

16. GILBERT L. 'Pharmacists have been left out of the loop': Exploring the role of pharmacists in the management of HIV/AIDS in South Africa. International Journal of Pharmacy Practice, 2016; 24(1): 40-48.

17. HIGGINS JPT, GREEN S. Cochrane Handbook for Systematic Reviews of Interventions. Volume 4 de Wiley Cochrane Series John Wiley \& Sons. 2011; 9781119964797: 672.

18. HOSSEINI Z, et al. Adherence to HIV/AIDS antiretroviral therapy among drug users: a qualitative study in Iran. Iran J Nurs Midwifery Res., 2016; 21: 29-37.

19. LIMA I, et al. Information and communication technologies for adherence to antiretroviral treatment in adults with HIV/AIDS. International Journal of Medical Informatics Publisher: Elsevier Ireland Ltd., 2016; 92: 54-61

20. MOLINO C, et al. HIV pharmaceutical care in primary healthcare: Improvement in CD4 count and reduction in drugrelated problems. Saudi Pharmaceutical Journal, 2017; 25(5): 724-733.

21. MORILLO-VERDUGO RM, et al. Influence of pharmacist intervention, based on CMO model, to improve activation in HIV patients. Journal of Managed Care and Specialty Pharmacy, 2018; 24(2): 165-172.

22. MORILLO-VERDUGO R, et al. Effect of a Structured Pharmaceutical Care Intervention Versus Usual Care on Cardiovascular Risk in HIV Patients on Antiretroviral Therapy: INFAMERICA Study. Annals of Pharmacotherapy, 2018; 52(11): 1098-1108.

23. MORILLO-VERDUGO R, et al. Development of a risk stratification model for pharmaceutical care in HIV patients. Farm Hosp., 2017 1; 41(3): 346-356.

24. OLERIBE O, et al. From decentralization to commonization of HIV healthcare resources: Keys to reduction in health disparity and equitable distribution of health services in Nigeria. Pan African Medical Journal. 2014; 24.

25. PRIMO LP. Gestão do cuidado em HIV/AIDS: impacto da atuação do farmacêutico clínico na adesão à terapia antiretroviral (TARV). Dissertação (Mestrado Profissional). Universidade de São Paulo: Gestão de Organizações de Saúde. Ribeirão Preto, 2015.

26. PRUST ML, et al. Patient and health worker experiences of differentiated models of care for stable HIV patients in Malawi: a qualitative study. PLoS One, 2018; 13(7): e0196498.

27. RAJESH V, et al. Relationship between adherence and health-related quality of life among HIV-patients in South Africa: findings and implications. Journal of AIDS and HIV Research, 2018; 10(8): 121-132.

28. SHRESTHA R, et al. A non-inferiority trial of an evidence-based secondary HIV prevention behavioral intervention compared to an adapted, abbreviated version: Rationale and intervention. Contemporary Clinical Trials, 2015; 44: 95102.

29. SURUR A, et al. Short-term effectiveness of a community health worker intervention for HIV-infected pregnant women in Tanzania to improve treatment adherence and retention in care: A cluster-randomized trial. PLoS ONE, 2017; 12(8).

30. SURUR A, et al. Health related quality of life of HIV/AIDS patients on highly active anti-retroviral therapy at a university referral hospital in Ethiopia. BMC Health Services Research, 2017; 17(1).

31. SYED I, et al. A qualitative insight of HIV/AIDS patients' perspective on disease and disclosure. Health Expectations, 2015; 18(6): 2841-2852.

32. TALL YRA, et al. An assessment of HIV patient's adherence to treatment and need for pharmaceutical care in Jordan. Int J Clin Pract., 2020; 00: e13509. 